\title{
Correction to: The Dollar Cycle of International Development, 1973-2017
}

\section{Ho-fung Hung ${ }^{1}$ Mingtang Liu ${ }^{1}$}

Published online: 9 December 2021

○) Springer Science+Business Media, LLC, part of Springer Nature 2021

\section{Correction to: Studies in Comparative International Development https://doi.org/10.1007/s12116-021-09346-5}

The original version of this article unfortunately contained mistakes in the formatting of Tables 2 and 3.

The errors are listed below:

1. In Table 2, the standard errors in parenthesis should be below the correlation coefficients.

2. In Table 3, the standard errors in parenthesis are properly placed below the correlation coefficients as they should be, but most of the columns are misaligned.

The original article has been corrected.

Publisher's Note Springer Nature remains neutral with regard to jurisdictional claims in published maps and institutional affiliations.

The original article can be found online at https://doi.org/10.1007/s12116-021-09346-5.

Ho-fung Hung

hofung@jhu.edu

Mingtang Liu

mliu69@jhu.edu

1 Department of Sociology, Johns Hopkins University, Baltimore, MD, USA 